\title{
Children's Walking to School: Driving and impeding factors
}

\author{
Mansoureh Rezasoltania, Mostafa Behzadfarb, Ismail Saidc \\ aArchitecture and Civil Engineering Department, Islamic Azad University Firoozkooh branch, Firoozkooh, Iran \\ ${ }^{b}$ School of Architecture and Environmental Design, Iran University of Science and Technology, Tehran, Iran \\ c Faculty of Built Environment, Universiti Teknologi Malaysia, Skudia, Johor, Malaysia \\ soltani@iaufb.ac.ir
}

\begin{abstract}
Motorized travel mode to school affects children's interaction with the environments in their journey that causes many consequences for them. With a focus on children's and parents' perception regarding the environment, this paper addresses some factors that affect children's travel mode choice in their school journey in Iran. The method used in this study was the analysis of collected data through questionnaire and interview. The results revealed the relations of three significant factors influencing children's walking mode choice in their school way. Identified factors can lead to design appropriate settings in their routes that can cause benefits for children and parents.
\end{abstract}

Keywords: Children's environment; Travel mode; School journey; Independent mobility

2398-4295 @ 2017 The Authors. Published for AMER ABRA by e-International Publishing House, Ltd., UK. This is an open access article under the CC BY-NC-ND license (http://creativecommons.org/licenses/by-nc-nd/4.0/). Peer-review under responsibility of AMER (Association of Malaysian Environment-Behaviour Researchers), ABRA (Association of Behavioural Researchers on Asians) and cE-Bs (Centre for Environment-Behaviour Studies), Faculty of Architecture, Planning \& Surveying, UniversitiTeknologi MARA, Malaysia.

http://dx.doi.org/10.21834/ajbes.v2i7.38 


\section{Introduction}

This paper is regarding children's walking and some important factors that affect children's walking travel mode choice in their neighborhood as their journey to and from school. Commuting to school and back is a daily activity for most children and their parents (Karsten and van Vliet, 2006) because of the compulsory nature of school attendance (Romero, 2010). In this regard, traveling between home and school can be seen as a critical area and also a significant opportunity to improve children's development as their travel behavior. Therefore, the journey to school is considered as a phenomenon that changes travel behavior and creates actual benefits for children and their parents.

Children's travel behavior is affected by social and physical environment factors as well as personal factors and family position (Timperio et al. 2006). Also, the beliefs, perceptions, and attitudes about different travel modes are likely to influence children's travel (Verplanken et al. 1994; Handy 1996; Kitamura et al. 1997; Bamberg and Schmidt 2003).

\section{Literature Review}

Home to school travel mode is categorized in different ways. One such way is that of accompaniment, which is divided into two parts, accompanied travel and unaccompanied travel. Moreover, regarding transportation type, children's travel modes to school are under two general categories, active and passive.

Active travel mode is divided into two types, walking and cycling (Hume 2006) and is known as a proper economic policy to go to school and back. Active transportation, in addition to health benefits, promotes a physically active lifestyle which is likely to continue to adulthood. However, it can be seen that nowadays children's active commuting to school has declined in many countries (Timperio et al. 2006). Children were not motivated to cycle because of risks that they may face in their ways such as accidents and theft, and also because of a lack of necessary facilities like biking and parking space. Also, using different active travel modes to school strongly depends on societal norms. For instance, in Iran, children are not pushed to cycle to school, especially girls, because of their tradition that prohibits girls from cycling.

A child's transportation mode is also influenced by perceived obstacles that affect parental decisions (Yeung et al. 2008). In this regard, physical attributes that impact a child's choice of travel mode to school including street layout, distance to school, and traffic counts have been studied based on adult concepts, and have disregarded variables which focus on children's interests (Jones et al. 2000; Braza et al. 2004; Ewing et al. 2004; Boarnet et al. 2005).

Moreover, the effects of environmental factors on children's school journey have mainly concentrated on the parents' perceptions of the environment, such as distance from home 
to school or traffic conditions (Bricker et al. 2002; Dellinger and Staunton 2002; Sjolie and Thuen 2002; Ziviani et al. 2004).

Parents' protective attitudes influence children's active travel modes in their school journey (Romero 2010). Parents' perceptions of the environment have an effect on their decision regarding children's travel mode to and from school. Moreover, the restriction on children's autonomy in their movement is considered a factor that plays a significant role in their travel mode choice (Romero 2010). Recently, many researchers such as Mackett et al. (2007), Ross (2007), Brown et al. (2008), Wen et al. (2009) have emphasized that children's walking to school without parental supervision and accompaniment has an effect on their skills and knowledge (Romero 2010).

Parents' protective role and their accompaniment with children can diminish opportunities to improve their flexibility (Hillman et al. 1990; Romero 2010). There are many reasons why parents limit their children's curiosity. Parents' perception and interpretation of social and environmental safety affect parents' anxiety (Rissotto and Tonucci 2002) which has an influence on their accompanying their children to school. Moreover, urban environmental conditions negatively affect children's independent mobility. Modern cities have been changed to negative space to live especially for children to explore the environmental opportunities. In other words, children's terrain for independent exploration of the space has been reduced (Karsten and van Vliet 2006). In this regard, there is growing evidence that higher level of independent mobility has a significant correlation with active commuting in primary school children (Panter et al. 2008). Therefore, children's school journey without parental accompaniment is seen as one of their activities that can be evaluated to determine their level of independent mobility (Hillman et al. 1990).

Regarding the relation of children's independent mobility and the time spent in their school journey, it is noteworthy that children who have the independent mobility to travel to school play for at least half an hour in their school journey (Wen et al. 2009). Staying more in school way is inconsistent with Prezza et al. (2001) and Romero (2010) who found that the time children spend in their way to and from school can be increased by enhancing their independent mobility.

Furthermore, those children who are mostly allowed to walk on their own, near where they live, are more than two and a half times more likely to spend time at least 30 minutes outside after school compared to those who are never allowed to walk on their own (Wen et al. 2009). Therefore, preparing various play features along the children's route to school can motivate them to stay and play in outdoor environments in their school way. Therefore, they are stimulated to choose to walk as travel mode and home-school journey as a context of walking (Rezasoltani et al. 2010).

The factors which affect children's independence in their decision to choose to walk as travel mode have often been studied. Besides, limited studies have been conducted concerning children's walking in their school journey. However, this paper aimed to investigate some important factors which influence children's walking travel mode choice in their way to and from school as well as their relation to parental limitations. 


\section{Methodology}

The research conducted for this paper used mixed method design. The rational to use this technique is to incorporate a qualitative component into a quantitative method to get a very powerful mix (Miles and Huberman 1994). Integrating a range of age-appropriate approaches into the research study can assist children to express their daily experiences (Matthews and Tucker 2000). For this purpose, written questionnaire as quantitative and face to face interview as a qualitative method was selected to determine children's preferences regarding walking to school. The questionnaire contained questions about children's transportation mode to and from school, their permission to travel without accompaniment, their preferences to play on their way to school and back, and permitted time for children to play in their journey to and from school.

Then, it was followed by the Open-ended interview to support the questionnaires and to clarify some of the children's responses, preferences, needs, and feelings towards their autonomous travel and play on the way to school. Nineteen children participated in face-to-face interview separately and away from the classroom with no teachers or other school authorities present. The results from the interviews contribute to support and complement the findings obtained by the analysis of the questionnaire.

\section{Results and Discussions}

A major part of the questionnaire concerned the children's travel mode to school, their permission to go to school without adult supervision and their preferences to take a trip on their own in their way to school. Therefore, the percentage of children's transportation to school provides insight into the possibility of play on their travels to and from school.

Principle Component Analysis (PCA) was utilized to determine the influential factors on students' travel behavior by affecting their play preference in their school journey. Three significant factors which influence children's walking to school and back were identified, including Parents' Limitation, Play Time, and Independent Mobility. To find the relationship among the obtained factors regarding both the strength of the relationship and the direction, correlation analysis was performed. By correlation analysis (Table 1), Parents' Limitation has high correlation coefficients with both Independent Mobility and Play Time. These high correlations refer to the significance of parental restrictions which negatively affect th e ir children's independent mobility to play freely on their way to school which in turn influences their enthusiasm to choose to walk as their travel mode to school.

Table 1: Factors' correlation matrix

\begin{tabular}{llccc}
\hline & & $\begin{array}{c}\text { Play } \\
\text { Time }\end{array}$ & $\begin{array}{r}\text { Parents' } \\
\text { Limitation }\end{array}$ & $\begin{array}{r}\text { Independent } \\
\text { Mobility }\end{array}$ \\
\hline \multirow{2}{*}{ Correlation } & Play Time & 1.000 & \\
\cline { 2 - 4 } & Parents' Limitation & $-.611^{* *}$ & 1.000 & \\
\hline
\end{tabular}




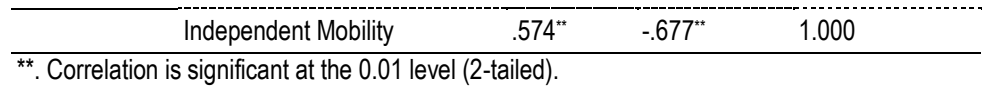

In other words, the higher restrictions from parents, the lower children's independent mobility is, and then the lower their interest to play on the way is.

A part of this finding is related to the relation of parental limitation, children's independent mobility, and travel mode seems to be inconsistent with Romero (2010) who found that parental restriction on children's autonomy of movement affects their travel mode. This finding is also by Rissotto and Tonucci (2002) and Karsten and van Vliet (2006) who argued that limited children's independent mobility on the i $r$ wa y to school is due to parents' anxiety about the environmental conditions. However, this paper found additional factors that influence the children's desire to walk to and from school.

Another important factor which influences children to walk to school is Independent Mobility. The correlation coefficient between Independent Mobility and Play Time is high $(0.574>0.5)$ and positive. This amount of correlation means that children's independent mobility has a positive effect as the children spend the time to play before and after school, which is a significant factor influencing their enthusiasm to walk to school. In other words, the more independent mobility a child has, the more time they spend playing on their way to school. This finding is in accordance with Prezza et al. (2001), Wen et al. (2009), and Romero (2010) who suggested that a number of time children spend in their school journey is affected by their degree of independent mobility.

Further, this research concluded that when children have autonomy of movement in their neighborhood, they are permitted to stay outdoors and play on their way to and from school. Then, when children have independence on their way to school, they are interested to be outdoors more to play, and that affects their travel behavior. The CFA model confirms the relationships among the obtained factors (Figure1). Moreover, the factor loadings shown in the model indicate to what extent the factors affect each other.

According to the model, Parental Limitation is the independent factor, and Play Time and Independent Mobility are dependent factors due to their effects from Parents' Limitation. Therefore, it is deduced that children's independent mobility on their way to school is deferred by parents' restriction; and children's play time on their school journey is directly affected by their parents' restrictions and indirectly affected by the amount of autonomy in their movement. From another aspect, Parental Limitation is considered an affecting factor, Play Time is an affected factor, and Independent Mobility is both affecting factor because of its effect on Play Time, and affected factor due to the effect by Parental Limitation (Figure 2). 


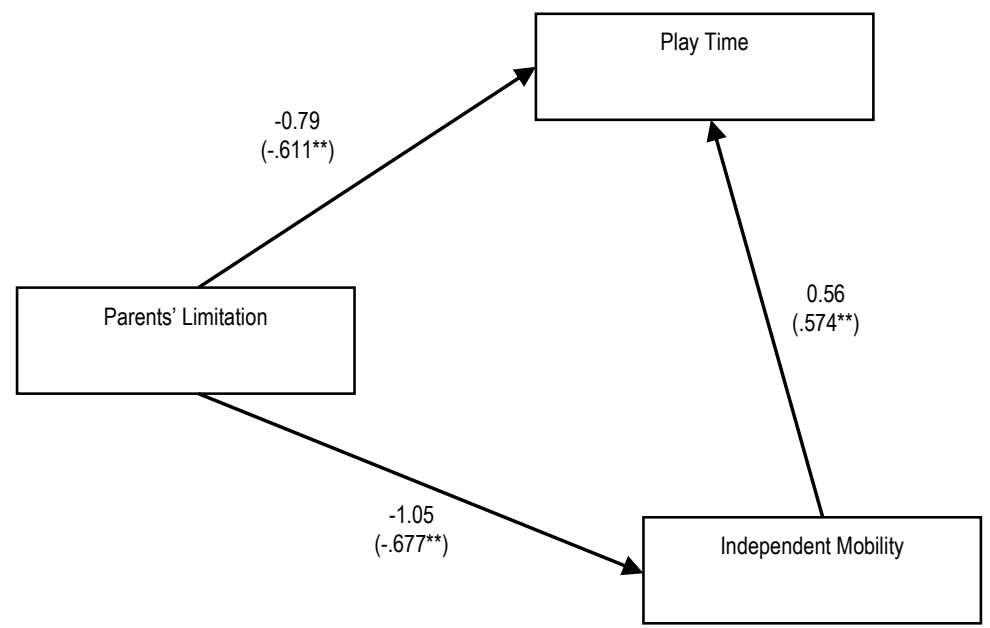

Figure 1: Fitted CFA model

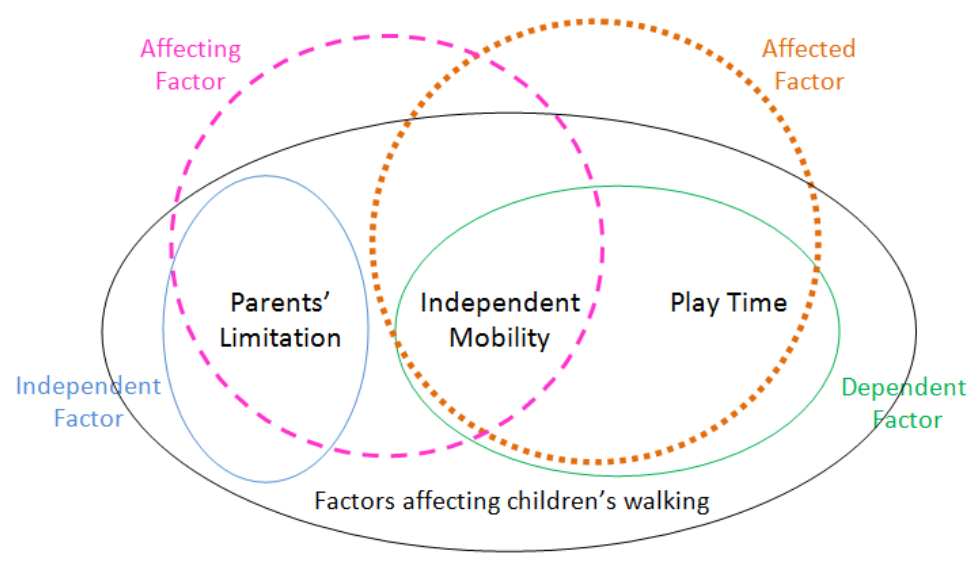

Figure 2: Factors' interrelationships

\section{Conclusion}

This paper focused on the factors influencing children's interests and preferences to choose to walk as school travel mode by an emphasis on the play during their 
school journey. Three significant factors were found to spark their interest in walking on their way comprising Parental Limitation, Independent Mobility, and Play Time. From these obtained factors, Parental Limitation as an independent factor is considered an impeding factor that negatively affects children's play on their way to and from school. Also, both Independent Mobility and Play Time as dependent factors are considered as motivators for children to play on their way, and then to choose to walk as their desired travel mode to school. Therefore, to increase the number of children who walk to school, the authorities, planners, and designers should notice to prepare suitable environmental conditions regarding children's play and independence with consideration given to their parents' protective role. In this regard, designing playgrounds in children's school way with many play features, and considering safety and security to decrease parents' anxiety can motivate children to choose active travel mode in their school journey.

\section{References}

Bamberg, S, \& Schmidt, P. (2003). Incentives, morality, or habit? Predicting students' car use for university routes with the models of Ajzen, Schwartz, and Triandis. Environment and Behavior, 35, 264-285.

Boarnet, M.G., Day, K., Anderson, C., McMillan, T., \& Alfonzo, M. (2005). California's Safe Routes to School program. Journal of the American Planning Association, 71, 301-317.

Braza, M., Shoemaker, W., \& Seeley, A. (2004). "Neighborhood Design and Rates of Walking and Biking to Elementary School in 34 California Communities." American Journal of Health Promotion, 19, 128-136.

Bricker, S.K., Kanny, D., Mellinger-Birdsong, A., \& Powell, K.E. (2002). School transportation modes-Georgia, 2000. Morbidity and Mortality Weekly Report, 51, 704-705.

Brown, B., Mackett, R., Gong, Y., Kitazawa, K., \& Paskins, J. (2008). Gender Differences in Children's Pathways to Independent Mobility. Children's Geographies, 6, 385-401.

Cobb, E. (1977). The Ecology of Imagination in Childhood. New York: Columbia University Press.

Dellinger, A.M., \& Staunton, C.E. (2002). Barriers to children walking and biking to school - United States, 1999. Journal of the American Medical Association, 288, 1343-1344.

Ewing, R., Schroeer, W., \& Greene, W. (2004). School Location and Student Travel: Analysis of Factors Affecting Mode Choice. Transportation Research Record, 1895, 55-63.

Handy, S.L. (1996). Methodologies for exploring the link between urban form and travel behavior. Transportation Research, 2, 151-165.

Harten, N., \& Olds, T. (2004). Patterns of active transport in 11-12 year old Australian children. Australian and New Zealand Journal of Public Health, 28, 167-172.

Hillman, M., Adams, J., \& Whitelegg, J. (1990). One False Move: a Study of Children's Independent Mobility. London, Publications of the Policy Studies Institute. 
Hume, C. (2006). What influences children's walking and cycling to school? Center for Physical Activity and Nutrition Research, Deakin University.

Jones, L., Davis, A., \& Eyers, T. (2000). Young People, Transport and Risk: Comparing Access and Independent Mobility in Urban, Suburban and Rural Environments. Health Education Journal, 59, 315-328.

Karsten, L., \& van Vliet, W. (2006). Increasing Children's Freedom of Movement: Introduction. Children, Youth and Environments , 16, 69-73.

Kegerreis. (1993). Independent mobility and children's mental and emotional development. In: M. Hillman (Ed.), Children' transport and the quality of life (pp. 28-34). London: Policy Studies Institute.

Kitamura, R., Mokhtarian, P.L., \& Laidet, L. (1997). A micro-analysis of land use and travel in five neighborhoods in the San Francisco Bay Area. Transportation , 24, 125-158.

Mackett, R., Brown, B., Gong, Y., Kitazawa, K., \& Paskins, J. (2007). Children's Independent Movement in the Local Environment. Built Environment, 33, 454-468.

Matthews, M.H. (1992). Making Sense of Place: Children's Understanding of Large Scale Environments. Hemel Hempstead: Harvester Wheatsheaf.

Matthews, H., \& Tucker, F. (2000). Consulting Children. Journal of Geography in Higher Education, 24, 299-310.

Miles, M., \& Huberman, M.A. (1994). Qualitative Data Analysis, (2nd Edition). Beverly Hills: Sage Publications.

Panter, J. R., Jones, A. P., \& van Sluijs, E. M. F. (2008). Environmental determinants of active travel in youth: a review and framework for future research. International Journal of Behavioral Nutrition and Physical Activity, 5, 34.

Rezasoltani, M., Said, I., Salami, B. (2010). Children's Independent Mobility in Home-School Way and Influential Factors on It. Paper presented at the 3rd International Graduate Conference on Engineering, Science, and Humanities. University Teknologi Malaysia, Malaysia.

Romero, V. (2010). Children's Views of Independent Mobility during Their School Travels. Children, Youth and Environments, 20, 46-66.

Ross, N.J. (2007). 'My Journey to School...' Foregrounding the Meaning of School Journeys and Children's Engagements and Interactions in their Everyday Localities. Children's Geographies, 5, 373-391.

Sjolie, A. N., \& Thuen, F. (2002). School journeys and leisure activities in rural and urban adolescents in Norway. Health Promotion International, 17, 21-30.

Timperio, A., Ball, K., Salmon, J., Roberts, R., Giles-Corti, B., \& Simmons, D. (2006). Personal, family, social, and environmental correlates of active commuting to school. American Journal of Preventive Medicine, 30, 45-51.

Verplanken, B., Aarts, H., van Knippenberg, A., \& van Knippenberg, C. (1994). Attitude versus general habit: antecedents of travel mode choice. Journal of Applied Social Psychology, 24, 285-300.

Wen, L.M., Kite, J., Merom, D., \& Rissel, C. (2009). Time Spent Playing Outdoors after School and Its Relationship with Independent Mobility: A Cross-Sectional Survey of Children Aged 10-12 Years in Sydney, Australia. The International Journal of Behavioral Nutrition and Physical Activity, 6, 15. 
Yeung, J., Wearing, S., \& Hills, A. P. (2008). Child Transport Practices and Perceived Barriers in Active Commuting to School. Transportation Research Part A, 42, 895-900.

Ziviani, J., Scott, J., \& Wadley, D. (2004). Walking to school: incidental physical activity in the daily occupations of Australian children. Occupational Therapy International ,11, 1-11. 